\title{
Sex chromosome polymorphism and heterogametic males revealed by two cloned DNA probes in the $\mathrm{ZW} / \mathrm{ZZ}$ fish Leporinus elongatus
}

\author{
Ichiro Nakayama ${ }^{1, *}$, Fausto Foresti ${ }^{2}$, Rita Tewari ${ }^{1}$, Manfred Schartl ${ }^{3}$, Daniel Chourrout ${ }^{1}$ \\ ${ }^{1}$ Institut National de la Recherche Agronomique, Laboratoire de Génétique des Poissons, F-78352 Jouy en Josas, France \\ 2 Universidade Estadual Paulista "Julio de Mesquita Filho", Departamento de Morfologia, CEP, 18618-000, Botucatu, Sao Paulo, Brazil \\ ${ }^{3}$ Theodor-Boveri-Institut für Biowissenschaften der Universität Würzburg, Lehrstuhl Physiologische Chemie I, \\ Am Hubland, D-97074 Würzburg, Germany
}

Received: 15 March 1993; in revised form: 19 October 1993/Accepted: 18. November 1993

\begin{abstract}
In order to study the divergence of teleost sex chromosomes, subtractive cloning was carried out between genomic DNA of males and females of the rainbow trout $(\mathrm{XX} / \mathrm{XY})$ and of Leporinus elongatus (ZW/ZZ). Inserts cloned in a plasmid vector were individually tested on Southern blots of DNA of males and females for sex specificity. No sex-specific insert was obtained from trout, but two out of ten inserts cloned from L. elongatus showed sex-specific patterns in this species: one corresponds to a sequence present on both $\mathrm{Z}$ and $\mathrm{W}$ chromosomes, while the other is W specific. Sequences of these two inserts show neither clear homology with other known sequences, nor an open reading frame. They cross-hybridize with the genomic DNA of Leporinus friderici, but without sex-specific patterns. Twenty-four $L$. elongatus adults were sexed by gonadal observation, chromosomed examination and Southern hybridization with one or the other insert. Ten males and 11 females had chromosomes and hybridization patterns typical of their sex. One ZW female was recognized as a male with the W-specific probe. This was also the case for two unusual $\mathrm{ZW}$ males, one having a male hybridization pattern with the other probe. These three atypical individuals may result from single genetic exchanges between four regions of the $\mathrm{Z}$ and the $\mathrm{W}$, giving rise to three atypical $\mathrm{W}$ chromosomes. Finding males with such atypical heterochromosomes in a female heterogametic species may indicate that a gradual transition occurs between the heterogametic systems.
\end{abstract}

\footnotetext{
* Present address: National Research Institute of Aquaculture, Tamaki, Mie, 519-04, Japan

Communicated by: E.R. Schmidt

Correspondence to: $\mathrm{D}$. Chourrout

$E M / B L$ accession number: Nucleic acid sequences of clones L'46 and L'5 have been submitted to the EMBL data library (Heidelberg, Germany) under accession numbers X68219 and X68220 respectively
}

\section{Introduction}

Fish are often considered as a primitive stage in the evolution of vertebrate sex determination, for several reasons: (i) a large number of fish species are hermaphroditic, although the majority of them have separate sexes (Smith 1975; Price 1984); (ii) in gonochoristic species, the course of sexual differentiation can be reversed artificially, the resulting gonad being functional (Yamamoto 1953; Hunter and Donaldson 1983); (iii) sex chromosomes have been cytologically detected in a minority of species (Sola et al. 1981; Beçak 1983). However, the assumption that sex determination is primitive in fish is weakened, when each of these three points is examined more thoroughly: (i) hermaphroditism is encountered in various orders, in which many closely related species are gonochoristic, suggesting that it reflects more a secondary adaptation than an ancestral situation; (ii) most cases of sex inversion are the result of steroid treatment, and few examples of environmental sex determination have been reported; (iii) chromosome banding (Haaf and Schmid 1984), sex-linked inheritance (Aida 1921), progeny testing after sex inversion (Yamamoto 1955) or induced gynogenesis (Nagy et al. 1978; Chourrout and Quillet 1982) have revealed sex chromosomes that were not detectable by classical cytogenetic methods.

It remains clear that fish sex chromosomes are less divergent morphologically than those of other vertebrates. An argument for a recent divergence is that male and female heterogamety may be found in the same order, the same genus, and more strikingly in the same species. The best documented case is the platyfish, which has three sex chromosomes (X, Y, W), and homogametic or heterogametic sex genotypes in both sexes (Gordon 1947; Foerster and Anders 1977; Kallman 1984). In the platyfish, female heterogamety has certainly appeared from an original male heterogametic system. Male heterogametic and female heterogametic species have also been observed within the Oreochromis genus (Hickling 1960; Clemens and Inslee 1968; Guerrero 1975), and within the Leporinus genus (Galetti et al. 1981). The 
morphological divergence of sex chromosomes is particularly clear in female heterogametic Leporinus species, but not visible in Oreochromis.

Molecular investigations may be more powerful than cytogenetics to study how fish sex chromosomes diverge. Hybridization of fish genomic DNA with heterologous sequences such as Bkm and ZFY has not revealed sexspecific patterns in the rainbow trout (Lloyd et al. 1989; Ferreiro et al. 1989), but hybridization with oligonucleotide probes did so in several poeciliids (Nanda et al. 1990, 1992). Subtractive cloning between genomes of males and females has demonstrated a $\mathrm{Y}$-specific repetitive sequence in chinook salmon (Devlin et al. 1991). In the present study, subtractive cloning was performed in the rainbow trout (male heterogametic species, in which the $\mathrm{X}$ and $\mathrm{Y}$ chromosomes are not always discernible; Thorgaard 1977, 1983) and in Leporinus elongatus (female heterogametic species, in which the $\mathrm{Z}$ and $\mathrm{W}$ chromosomes are easily recognized; Galetti and Foresti 1986). Two sex-specific probes have been cloned in $L$. elongatus, and used to investigate the structure and variability of sex chromosomes.

\section{Materials and methods}

Animal collection, gonadal and chromosomal sexing. Rainbow trout belonged to a domestic strain maintained in the INRA fish farm of Gournay sur Aronde, and selected for spawning in spring. Sexually mature adults of $L$. elongatus were captured in the Tiete river (close to Barra Bonita, State of Sao Paulo, Brazil), during their upstream migration. Fish were bled for DNA extraction. Individuals of $L$. elongatus were also subjected to chromosome preparation: kidney cell suspensions were subjected to in vitro treatment with colchicine at $0.6 \mu \mathrm{g} / \mathrm{ml}$ in Hank's saline solution for $15 \mathrm{~min}$, and to hypotonic treatment in $75 \mathrm{mM} \mathrm{KCl}$ for $35 \mathrm{~min}$ at $37^{\circ} \mathrm{C}$. After fixation with 3:1 (v/v) methanol:acetic acid, cells were dropped onto slides and stained with Giemsa. All fish were sexed by examination of gonads. To confirm the sex in $12 \mathrm{~L}$. elongatus adults, their gonads were fixed in Bouin fixative for $12 \mathrm{~h}$, and then subjected to routine histological procedures including haematoxylin-eosin staining. Two samples of Leporinus friderici adults were collected in Brazil and French Guyana, sexed by macroscopic examination of the gonads and bled for DNA extraction.

DNA extraction and subtractive hybridization. Five hundred microlitres of total blood was diluted in $25 \mathrm{ml}$ of TNES-urea $(10 \mathrm{mM}$ Tris- $\mathrm{HCl}, \mathrm{pH} 7.4,120 \mathrm{mM} \mathrm{NaCl}, 10 \mathrm{mM}$ EDTA, pH $8.0,0.5 \%$ SDS, $4 \mathrm{M}$ urea). After several days or weeks at ambient temperature, proteinase $\mathrm{K}$ was added at a final concentration of $150 \mu \mathrm{g} / \mathrm{ml}$ and the solution was incubated overnight at $37^{\circ} \mathrm{C}$. This was followed by three phenol-chloroform and three chloroform extractions. After precipitation with $2 \mathrm{vol}$. ethanol, the pellet was rinsed in $80 \%$ ethanol, moderately dried and dissolved in TE.

Subtractive hybridization was performed in trout with the DNA of five males and five females, and in L. elongatus with the DNA of eight males and one female. The general method was that described by Lamar and Palmer (1984), who renatured DNA of the heterogametic sex digested with Sau3A (Boehringer-Mannheim; 5 units $/ \mu \mathrm{g}$ ) with a large excess of sonicated DNA from the homogametic sex. Preliminary experiments led us to sonicate DNA (kept on ice) for $18 \mathrm{~s}$ each minute over $5 \mathrm{~min}$ at the maximal power of the Branson Sonifier Cell Disruptor B15 (resulting average size, $500 \mathrm{bp}$ ). Sonicated and digested DNA was precipitated with ethanol and dissolved in water. For each species, $1 \mathrm{mg}$ of sonicated DNA (homogametic sex) was mixed with $10 \mu \mathrm{g}$ of digested DNA (heterogametic sex), and the mixture was denatured in the following sequence: $8 \mathrm{~min}$ at $100^{\circ} \mathrm{C}, 2 \mathrm{~min}$ at $0^{\circ} \mathrm{C}, 2 \mathrm{~min}$ at $100^{\circ} \mathrm{C}$, and a prolonged stay at $0^{\circ} \mathrm{C}$. The renaturation took place for 3 days at $68^{\circ} \mathrm{C}$ in $200 \mu \mathrm{l}$ of rapid renaturation buffer $(2 \mathrm{M}$ ammonium sulphate, $50 \mathrm{mM}$ disodium phosphate, $5 \mathrm{mM}$ EDTA, $\mathrm{pH}$ 6.8) as used by Lamar and Palmer (1984). The renatured mixture was then dialysed against TE buffer, precipitated with ethanol and dissolved in TE buffer for ligation in the plasmid.

Cloning and collection of inserts. In general, molecular biological methods were performed as described by Sambrook et al. (1989). pUC19 was cut with BamHI, dephosphorylated, and mixed with renatured genomic DNA in ligation buffer $[200 \mathrm{ng} p U C, 3 \mu \mathrm{g}$ genomic DNA, 4 units of Boehringer-Mannheim T4 DNA ligase, in $66 \mathrm{mM}$ Tris- $\mathrm{HCl}, 5 \mathrm{mM} \mathrm{MgCl} 2,1 \mathrm{mM}$ dithioerythritol (DTE), $1 \mathrm{mM}$ ATP, pH 7.5; total volume $20 \mu \mathrm{l}$; treatment overnight at $15^{\circ} \mathrm{C}$. Four microlitres of this solution was used to transform $200 \mu \mathrm{l}$ of the DH5 $\alpha$ Max Efficiency Escherichia coli strain (Gibco), under conditions recommended by the manufacturer. White colonies, which do not express the lac $Z$ gene, were screened for the presence of inserts by restriction analysis, using EcoRI + HindIII, and putative inserts were extracted from agarose minigels with the Geneclean purification kit (Bio 101).

Tests of insert sex specificity. Southern blots were performed with digested DNA run on $0.8 \%$ agarose gels $(20 \mu \mathrm{g}$ per well; $1 \times \mathrm{TBE}$, $2-3 \mathrm{~V} / \mathrm{cm}$ at $4^{\circ} \mathrm{C}$ for $16-24 \mathrm{~h}$ ). DNA transfer onto Zetaprobe membranes (Biorad) was carried out as recommended by the manufacturer, according to the general method of Southern (1975). Inserts were labelled with $\mathrm{dCT}^{32} \mathrm{P}$ (Amersham) using the BoehringerMannheim random priming kit, eluted with Qiagen tip 5 columns, and finally denatured for $5 \mathrm{~min}$ at $68^{\circ} \mathrm{C}$ in $50 \mathrm{mM} \mathrm{NaOH}$ before hybridization in the buffers successively recommended by Biorad for Zetaprobe membranes (Blotto; see Johnson et al. 1984; in which $6 \times$ SSC was replaced by $2 \times$ SSPE; and more recently by $400 \mathrm{mM} \mathrm{NaH}{ }_{2} \mathrm{PO}_{4}-\mathrm{HCl}$, pH 7.2, 7\% SDS, $1 \mathrm{mM}$ EDTA; $3 \times 10^{6} \mathrm{cpm} / \mathrm{ml}$ ). Hybridization was carried out for $18 \mathrm{~h}$ at $68^{\circ} \mathrm{C}$ (prehybridization was carried out in the same buffer for 1-4h). Membranes were washed in decreasing concentrations of SSC $(2 \times$ to $0.1 \times), 0.1 \% \operatorname{SDS}(1 \times$ SSC is $0.15 \mathrm{M} \mathrm{NaCl}, 0.015 \mathrm{M}$ Sodium citrate) and more recently in decreasing concentrations of SDS ( $7 \%$ to $1 \%$ ), $40 \mathrm{mM} \mathrm{NaH}{ }_{2} \mathrm{PO}_{4} \mathrm{pH} 7.2,1 \mathrm{mM}$ EDTA. Autoradiographic exposure was for 1 to 7 days at $-60^{\circ} \mathrm{C}$, with Amersham hyperMP films.

In situ hybridization on chromosomes. Slides were treated with RNase $\left(100 \mu \mathrm{g} / \mathrm{ml}, 2 \times \mathrm{SSC}\right.$ for $1 \mathrm{~h}$ at $\left.37^{\circ} \mathrm{C}\right)$, dehydrated through an alcohol series and subjected to denaturation and hybridization as described by Seibl et al. (1990) and Zhang et al. (1990) with a few modifications. Briefly, $50 \mu$ l of hybridization solution $(2 \times$ SSC, $50 \%$ formamide, $1 \%$ Denhardt's, $0.1 \%$ SDS, $20 \mathrm{mM}$ $\mathrm{NaH}_{2} \mathrm{PO}_{4}, 20 \mathrm{mM} \mathrm{Na} \mathrm{HPO}_{4}, \mathrm{pH} 6.8,100 \mu \mathrm{g} / \mathrm{ml}$ sonicated $E$. coli DNA and $15-20 \mathrm{ng} / \mathrm{ml}$ labelled probe) was applied to each slide for $16-18 \mathrm{~h}$ at $42^{\circ} \mathrm{C}$ in a moist chamber. Probe L' 46 was labelled with dUTP-digoxigenin (Dig) and purified, as described for the kit (Boehringer-Mannheim; see also Kessler et al. 1990). Slides were then treated with blocking agent $(0.5 \%)$ prepared in buffer I $(100 \mathrm{mM}$ Tris- $\mathrm{HCl}, \mathrm{pH} 7.5,150 \mathrm{mM} \mathrm{NaCl})$ for $1 \mathrm{~h}$, incubated for $1-2 \mathrm{~h}$ at room temperature with diluted Dig-CIAP $(1: 1,000)$, washed for $2 \times 20 \mathrm{~min}$ in buffer I and $10 \mathrm{~min}$ in buffer III $(100 \mathrm{mM}$ Tris- $\mathrm{HCl}, \mathrm{pH} 9.5,100 \mathrm{mM} \mathrm{NaCl}, 50 \mathrm{mM} \mathrm{MgCl} 2$ ) and finally incubated for $3-4 \mathrm{~h}$ in colour developing solution (nitroblue tetrazolium/5-bromo-4-chloro-3-indolyl phosphate) as recommended in the kit. Reaction was stopped in TE and slides were stained for $2-4 \mathrm{~min}$ in $2 \%$ Giemsa.

Sequencing. Restriction fragments were subcloned into pBluescript $\mathrm{KS}+$ (Stratagene). Nucleotide sequences were determined by the dideoxy-chain termination procedure (Sanger et al. 1977) from double-stranded DNA using a modified T7 DNA polymerase (Sequenase, USB) on both strands. Sequence data were analysed using the University of Wisconsin sequence analysis program package GCG (Devereux et al. 1984). 


\section{Results}

\section{Genomic subtraction in the rainbow trout}

A differential gene bank was prepared from DNA of five males digested with Sau3A mixed with an excess of sonicated DNA from five females. After denaturation and prolonged renaturation of the mixture, ligation in pUC19 and five successive transformations of $E$. coli were performed. The number of ampicillin-resistant colonies recovered varied greatly among the different transformations, the last providing more than $86 \%$ of the total $(13 ; 780)$. In the presence of 5 -bromo-4-chloro-3indolyl- $\beta$-D-galactopyranoside + isopropyl-1-thio- $\beta$-Dgalactopyranoside (XGal+IPTG), white colonies always represented a small minority $(1.1 \%-10.1 \%$; average $1.4 \%$ ), suggesting that few inserts of significant size had been cloned. This was confirmed by restriction analysis of extracted plasmids, and we concentrated our efforts on HindIII + EcoRI fragments longer than $100 \mathrm{bp}$. Thirty-four were labelled and hybridized with trout genomic DNA digested with TaqI, and 17 provided clear bands. In no case however, could we observe a clear and repeatable sex-specific pattern (data not shown).

\section{Genomic subtraction in L. elongatus}

A differential gene bank was prepared from DNA from the first group of fish collected in Brazil, where they had been sexed by macroscopic observation of the gonads and later on using kidney chromosome preparations. The denatured and renatured solution contained $1 \mathrm{mg}$ of sonicated DNA from one female (1001) and an equimolar mixture of digested DNA from eight males $(1002,1020,1021,1022,1026,1029,1030,1031)$. Two consecutive transformations were performed, which gave rise to $1.3 \%$ and $3.4 \%$ white colonies in the presence of XGal + IPTG. Ten inserts were extracted, radiolabelled and hybridized to HaeIII digested DNA of 24 L. elongatus individuals. Clear hybridization bands were observed with seven of them, and the patterns were clearly sex specific for two inserts (L'5 and L'46). The L'5 and L'46 inserts were each tested on 24 L. elongatus individuals, out of which 13 had been sexed macroscopically (series $1000 ; 8$ males already referred to and $5 \mathrm{fe}$ males) and 11 microscopically (series 1200; 4 males and 7 females).

\section{L'5 insert}

Digestion of this insert with HindIII + EcoRI resulted in three fragments, because it contains one internal site for each enzyme. An equimolar mixture of these fragments was labelled and used for hybridizations. Two distinct patterns (illustrated by Fig. 1 for 13 fish) were observed for all 24 individuals available: one with three bands $(0.5,1.5$ and $2 \mathrm{~kb})$ in the 12 females and 1 male (1026), and the other with two of these bands ( 0.5 and $1.5 \mathrm{~kb})$ in 11 males. These two bands were more intense

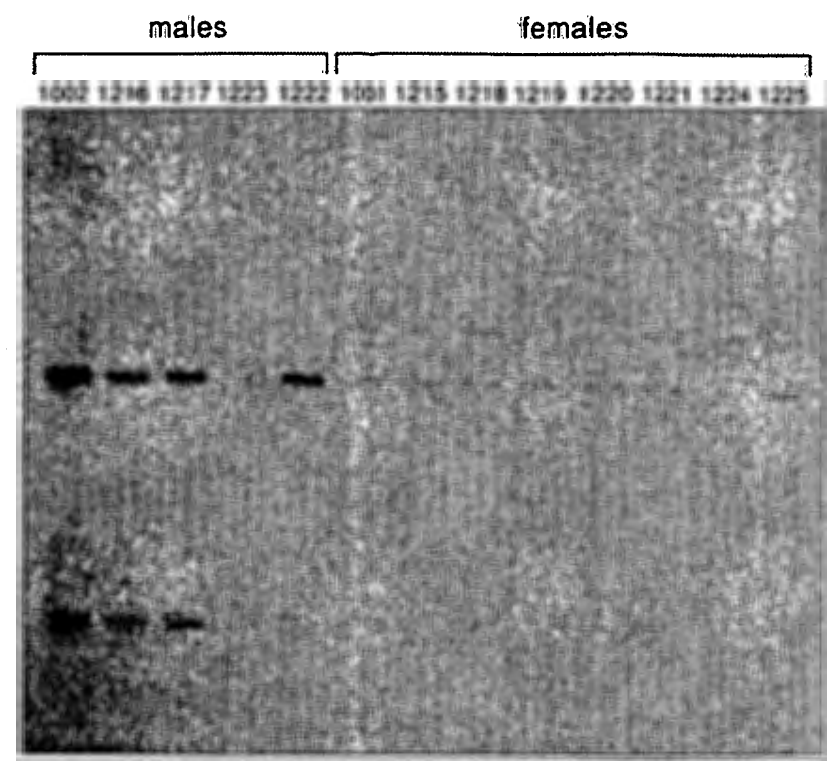

Fig. 1. Hybridization patterns of the L'S insert (isolated by subtractive cloning) with genomic DNA of five males and eight females of Leporinus elongatus, digested with HaellI. The typical male pattern has two bands $(0.5$ and $1.5 \mathrm{~kb})$, most likely representing a $\mathrm{Z}$ chromosome sequence. The typical female pattern has one additional band $(2 \mathrm{~kb})$ probably originating from the homologous sequence on the $\mathrm{W}$ chromosome. The 0.5 and $1.5 \mathrm{~kb}$ bands are less intense in females than in males (except in male 1223, for which less DNA was run, as checked on the gel after ethidium bromide staining). Exceptions are not presented on this blot

in the male pattern, suggesting that they correspond to a sequence on the $\mathrm{Z}$ chromosome. The other band $(2 \mathrm{~kb})$, found in only one male, should correspond to a sequence on the $\mathrm{W}$ chromosome. Sequencing revealed that L'5 contains an internal HaeIII site, which may explain the two HaeIII patterns as allelic differences at a single locus of the two sex chromosomes. In this case, HaeIII would not cut the $2 \mathrm{~kb}$ sequence of the W chromosome, and would cut that of the $\mathrm{Z}$ resulting in 0.5 and $1.5 \mathrm{~kb}$ fragments. L'5 is $729 \mathrm{bp}$ long and contains neither extended open reading frames nor obvious terminal repeats (Fig. 4). Comparisons with the Genbank and EMBL databases revealed no conspicuous similarity to any known sequence. Correlation between gonadal sex, hybridization pattern with the L'5 insert and chromosomal sex showed two unusual cases. One was male 1026, which had a female hybridization pattern (not shown in Fig. 1), but was also recognized as ZW by chromosomal examination. The second exception was male 1222 , which had a male hybridization pattern with L'5, but also an unusual ZW constitution.

\section{L'46 insert}

This insert was cut out as one fragment by EcoRI+ HindIII digestion. Two hybridization patterns were observed with HaeIII digested DNA from all 24 individuals available (illustrated in Fig. 2, for the same 13 fish as Fig. 1). For 11 of the 12 females, an intense signal was 


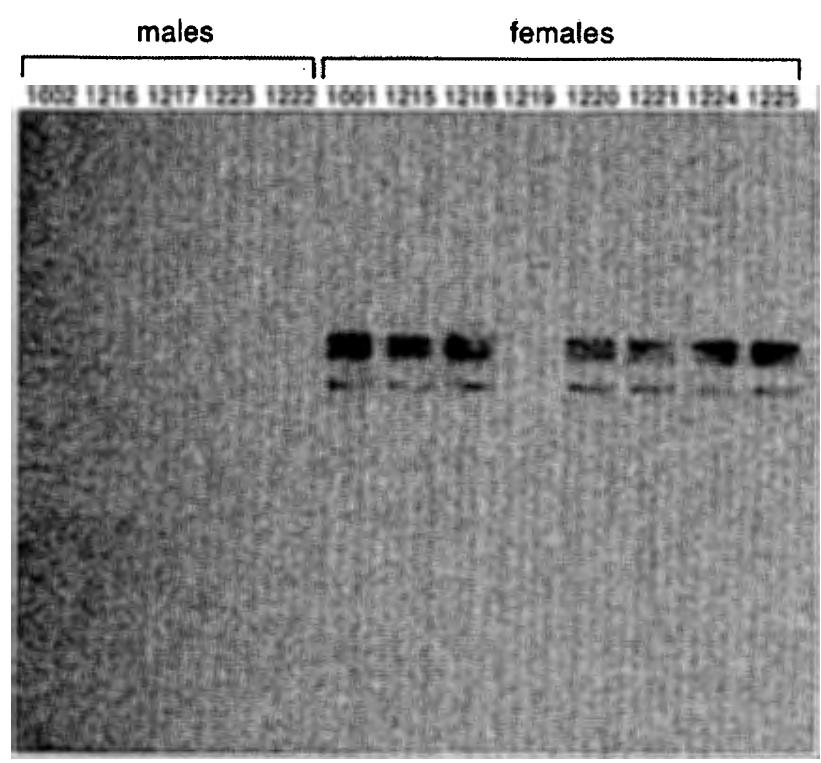

Fig. 2. Hybridization patterns of the L'46 insert (isolated by subtractive cloning) with genomic DNA of five males and eight females of Leporinus elongatus, digested with HaeIII. An intense signal is generally observed in females only (between levels 3 and $4.4 \mathrm{~kb}$ ) and most likely represents W-specific sequences. However, a minority of atypical individuals do not show this signal, although they possess a W chromosome (ZW female 1219, and two unusual $\mathrm{ZW}$ males not presented on this blot)

shared between three bands representing fragments of comparable molecular weight $(3,3.7$ and $4.4 \mathrm{~kb})$. This signal of an undoubtedly repetitive sequence was not found for all males or for female 1219 (shown in Fig. 2). This suggested that it was usually located on the W chromosome, without clear homologous sequences on the $\mathrm{Z}$ chromosome or on the autosomes. However, washing at lower stringency resulted in much fainter, multiple bands being observed for all individuals, irrespective of their sex. Correlation of hybridization patterns with the chromosomal and gonadal sexes drew our attention to

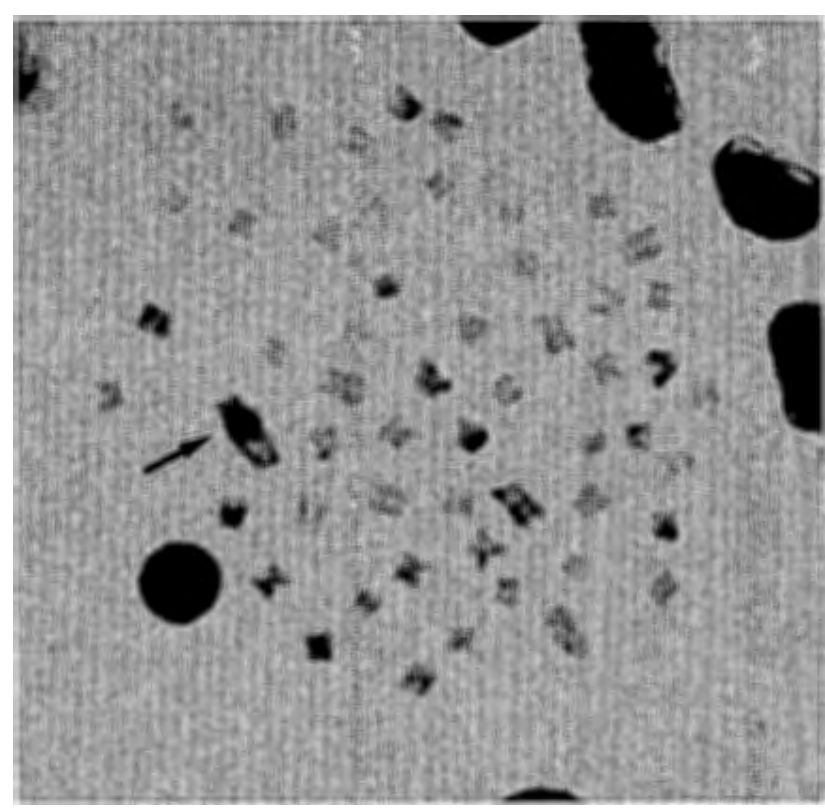

Fig. 3. In situ hybridization of the L'46 insert with Leporinus elongatus female mitotic chromosomes. The intense signal (arrow) is located on the proximal part of the W chromosome long arm

three individuals having a $\mathrm{ZW}$ karyotype but a male pattern with L'46: one was female 1219 and the two others were males 1026 and 1222 . In situ hybridization could be carried out on six females $(1215,1218,1224$, $1232,1263,1266)$ and three males $(1216,1256,1430)$. An intense signal was visible on the proximal part of the $\mathrm{W}$ chromosome long arm and in interphase nuclei of females, while no signal could be recognized in male cells (Fig. 3). Slides of animals 1219, 1026 and 1222 were not made available for in situ hybridization. This method has not been attempted with the other insert. L'46 is $174 \mathrm{bp}$ long and contains neither extended open reading frames nor obvious terminal repeats (Fig. 4). Comparisons with the Genbank and EMBL databases re-

\section{- L'46 insert}

1 gGATCCATAG TACCTTtTAA GTACCTCAGT AAGTGTtTTG CAGCCGTCCA ATGCTGTTGC 61 TTTGGTTCTG CCAAGTGTTG TGATAGCTTA CTAACTATCC AACTCAAATC GGGTCTGGTA 121 CATGTCATGA TGTATATCAA GCTACCCACT ATCTCTCTGT AACCTGTTGG ATCC
- L'5 insert

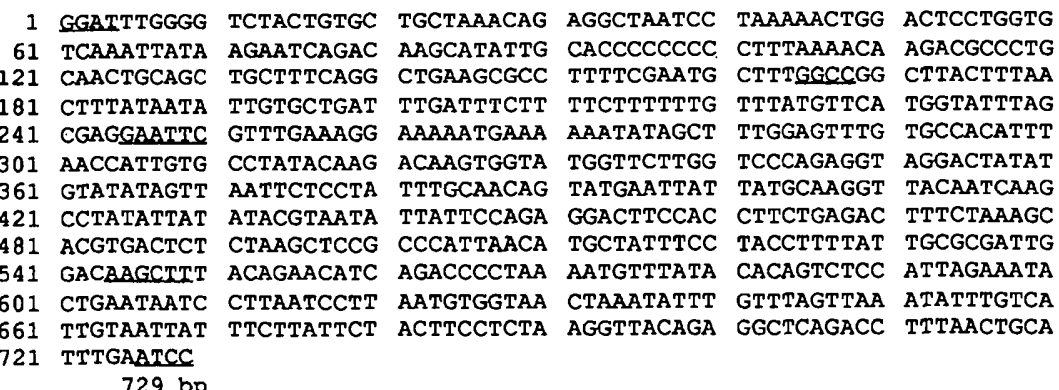
729 bp
Fig. 4. Nucleotide sequences of the two sexspecific inserts isolated in Leporinus elongatus. HindIII and EcoRI restriction sites are underlined. The internal HaeIII site of the L'S insert is also underlined 
vealed no conspicuous similarity to any known sequence. L'46 is also unrelated to L'5.

\section{Synthesis of hybridization pattern, and chromosomal and gonadal sex in L. elongatus}

Twenty-one individuals (out of 24) showed clear gonadal sex, karyotype, and hybridization patterns with the two inserts (Table 1). One female (1219) with a ZW karyotype was recognized as a female using the L'5 insert, but as a male using the L'46 insert. In the two males with unusual ZW karyotypes, one (1222) was recognized twice as a male with the probes, and the other presented a female pattern with L'5 and a male pattern with L' 46.

\section{Hybridization of L'S and L'46 with $L$. friderici and rainbow trout $D N A$}

Hybridizations were attempted on two populations of $L$. friderici collected from Brazil and French Guyana. When the L'5 insert was tested, this resulted in one intense band for DNA of all males and females from Guyana after digestion by HaeIII (Fig. 5), and essentially two bands after digestion with TaqI (not shown; a single band for one female was found however). In contrast, insert L' 46 provided multiple bands in each population, with the specimens from Guyana exhibiting a remarkable polymorphism after digestion with HaeIII (Fig. 5). However, none of the patterns observed in $L$. friderici was correlated with sex. No clear hybridization was observed after hybridization of these two probes
Table 1. Compilation of data obtained by chromosome observation and hybridization with the two sex-specific probes in 12 phenotypic males and 12 phenotypic females of Leporinus elongatus

\begin{tabular}{lllll}
\hline $\begin{array}{l}\text { Fish } \\
\text { no. }\end{array}$ & $\begin{array}{l}\text { Sex } \\
\text { gonad }\end{array}$ & $\begin{array}{l}\text { Sex } \\
\text { chromosome }\end{array}$ & $\begin{array}{l}\text { H.P. } \\
\text { L'5 }\end{array}$ & $\begin{array}{l}\text { H.P. } \\
\text { L'46 }\end{array}$ \\
\hline 1002 & M & ZZ & m & m \\
1020 & M & ZZ & m & m \\
1021 & M & ZZ & m & m \\
1022 & M & ZZ & m & m \\
1029 & M & ZZ & m & m \\
1030 & M & ZZ & m & m \\
1031 & M & ZZ & m & m \\
1216 & M & ZZ & m & m \\
1217 & M & ZZ & m & m \\
1223 & M & ZZ & m & m \\
1026 & M & ZW & f & m \\
1222 & M & ZW & m & m \\
1001 & F & ZW & f & f \\
1019 & F & ZW & f & f \\
1023 & F & ZW & f & f \\
1024 & F & ZW & f & f \\
1025 & F & ZW & f & f \\
1215 & F & ZW & f & f \\
1218 & F & ZW & f & f \\
1220 & F & ZW & f & f \\
1221 & F & ZW & f & f \\
1224 & F & ZW & f & f \\
1225 & F & ZW & f & f \\
1219 & F & ZW & f & m \\
\hline
\end{tabular}

Gonads of individuals 1001 to 1031 were sexed de visu, while those of individuals 1215 to 1225 were histologically sexed. In columns H.P. L'5 (hybridization pattern with L'5) and H.P. L'46 (hybridization pattern with $\left.L^{\prime} 46\right)$, male (m) and female (f) patterns are defined as those observed for the majority of phenotypic males and females respectively. The designations of three individuals showing atypical data are italicised

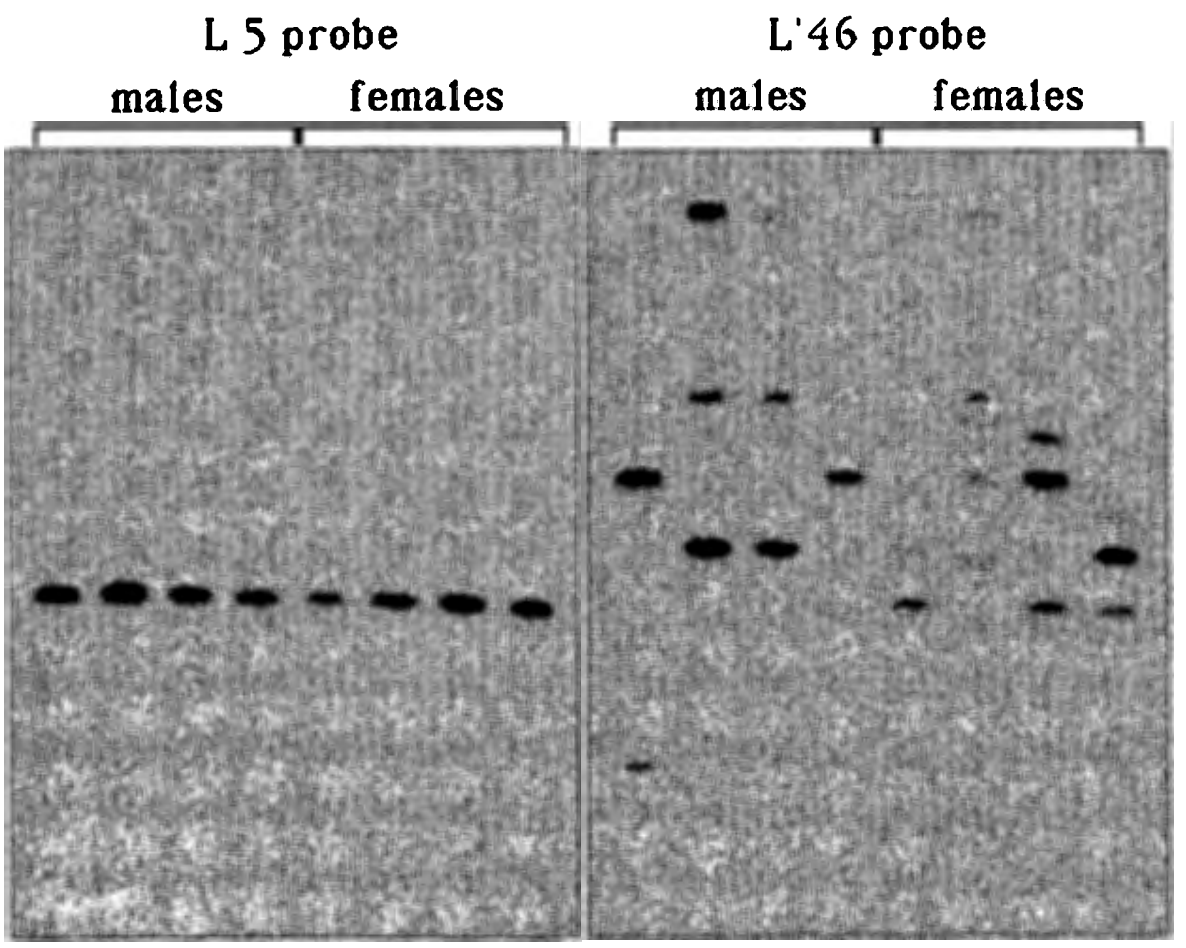

Fig. 5. Hybridization patterns of the L'5 insert and L'46 insert (isolated by subtractive cloning in Leporinus elongatus) with HaeIII digested genomic DNA of four males and four females of a $\mathrm{Le}$ porinus friderici population from French Guyana. A single band and a polymorphic pattern are observed with the L'5 and L'46 inserts respectively. However, none of these patterns is correlated with sex 
with DNA of rainbow trout males and females (not shown).

\section{Discussion}

\section{Subtractive cloning efficiency}

Two inserts hybridizing differently with males and females of $L$. elongatus were rapidly obtained using a classical subtractive cloning method (Lamar and Palmer 1984). This success contrasts with the failure to isolate such sequences in rainbow trout. These variable results may be explained by the slight morphological differentiation of sex chromosomes in the rainbow trout on the one hand, and by the pronounced sex chromosome differentiation in L. elongatus on the other hand. However, the number of inserts tested in both species is small, and subtractive cloning yields for the two species do not differ statistically $(0 / 34$ sex-specific inserts in trout; 2/10 in Leporinus). Devlin et al. (1991) have found 1 male-specific insert out of 18 tested after subtractive hybridization in chinook salmon, in which no sex chromosomes have been detected cytologically. This yield was equally low in similar attempts in mammals using almost identical techniques (3/24 in mouse by Lamar and Palmer 1984; $1 / 131$ in cattle by Cotinot et al. 1991). Therefore, it seems that a large amount of DNA unrelated to sex can enter the cloning vector and subsequently provide white bacterial colonies. This is in agreement with some of our preliminary observations (not described here), that subtraction between homogametic sex (Sau3A digestion) and homogametic sex (sonication) provides white colonies at the same order of magnitude as does subtraction between heterogametic sex (Sau3A digestion) and homogametic sex (sonication).

\section{Significance of isolated sequences}

The L'5 probe hybridizes with both the $\mathrm{Z}$ and $\mathrm{W}$ chromosomes, whereas L'46 is part of a W-specific chromosomal region. These two sequences isolated in L. elongatus do not seem to have a biological significance, since they are not part of a coding sequence and do not show clear homology with known sequences. Moreover, they do not produce sex-specific patterns when hybridized with the DNA of either closely related (L. friderici) or distantly related (rainbow trout) fish species. Thus, they may result from a recent accumulation of sequences in the $L$. elongatus genome, directly or indirectly favouring the divergence of sex chromosomes. This is in perfect agreement with a "Muller's ratchet"-like process leading to accumulation of elements where genetic exchange is absent, and thus to morphologically distinct chromosomes, which in their turn fix the heterogametic sex determination (Charlesworth 1991). Obviously, this mechanism could have worked for a sequence like L'46 (highly repetitive and $\mathrm{W}$ specific). The L' 5 case appears different, since a female specific restriction fragment length polymorphism (RFLP) due to the loss of an internal
HaelII site may explain the differences in hybridization patterns. However, these differences might also result from other events, compatible with a Muller's ratchet process, for instance the integration of a DNA fragment in the original L'5 sequence. It is noteworthy that no sex chromosomes have been detected cytologically in $L$. friderici (Galetti et al. 1984). Such a difference between two closely related species shows that Muller's ratchet can work very quickly to produce morphologically distinct sex chromosomes. In this respect, hybridization of these two inserts with other Leporinus species having a large W chromosome would be of great interest. An $\mathrm{XX} / \mathrm{XY}$ chromosome complement has been reported in another Leporinus species, which would also deserve a test with the L'5 and L'46 inserts (Galetti et al. 1981).

\section{Atypical sex chromosomes in three $Z W$ individuals}

Whatever the evolutionary significance of these two sequences, their hybridization patterns with our L. elongatus collection provided novel information. In 21 out of 24 individuals, we found the expected associations for each sex between these patterns, the sex chromosomes and the gonads. Interestingly, this association was disrupted in three individuals cytologically classified as $\mathrm{ZW}$, but which did not hybridize with L'46. Two of these individuals were $\mathrm{ZW}$ males, never detected in earlier cytogenetic studies of the species. Progeny testing of these males would have resulted in interesting information on their genetic sex, but reproduction of L. elongatus in captivity remains difficult. However, they were not ordinary genetic males, since they possessed a W chromosome. They were not ordinary genetic females either (environmentally sex reversed in phenotypic males), since they were not recognized by L' 46 . In other words, we may speculate that males 1026 and 1222 had an atypical $W$ chromosome devoid of the L'46 region and of a putative sex-determining locus. The $\mathrm{W}$ chromosome of male 1222 had in addition an L'5 region typical of the $\mathrm{Z}$ chromosome. In contrast, the $\mathrm{W}$ chromosome of the third exception (female 1219) would have retained its typical L'5 region with the female-determining locus, but lost the L'46 region.

\section{Genetic exchanges and the origin of atypical $W$ chromosomes}

The interest of these three cases lies in the fact that they can be interpreted by single genetic exchanges in female meiosis occurring between four regions of the sex chromosomes and giving rise to three atypical W chromosomes (W1, W2 and W3; see Fig. 6). These regions would be, in order of position on the normal W chromosome, the L'46 region, the female-determining locus, the L'5 region, and the segment of the long arm determining $\mathrm{W}$ chromosome morphology (Ws) and its cytogenetic identification as such. C-banding studies have suggested that the difference in size between the L. elongatus $\mathrm{Z}$ and $\mathrm{W}$ chromosomes is basically due to 

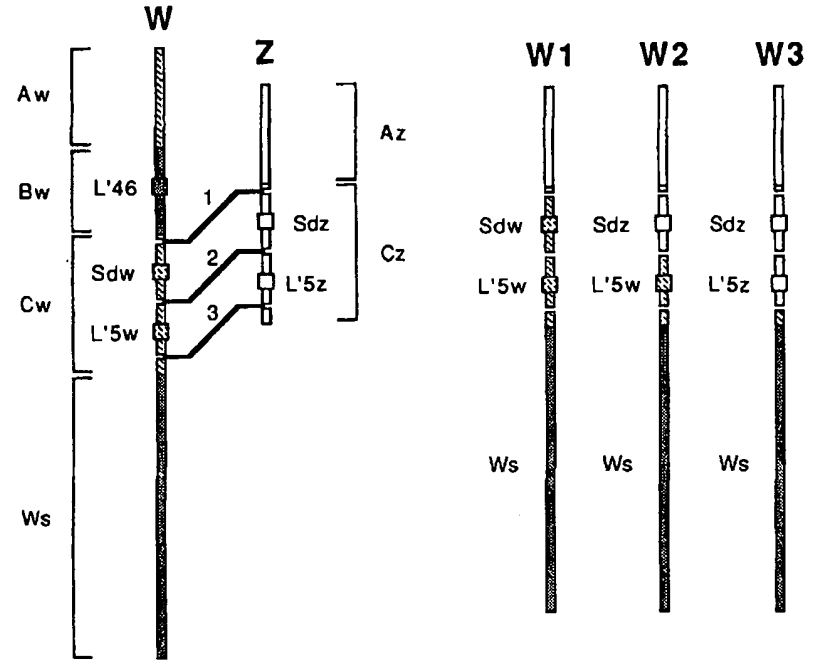

Fig. 6. Model explaining the presence of three atypical individuals in the collection of Leporinus elongatus. Both sex chromosomes possess a homologous region $(\mathrm{Cw}=\mathrm{Cz})$ containing a sex-determining locus (Sd with two alleles $\mathrm{Sdw}$ and $\mathrm{Sdz}$ ) and the L'5 locus (alleles L'5w and L'5z), in which crossovers take place. Two regions of the W long arm, one proximal bearing the L'46 locus $(\mathrm{Bw})$ and another long and distal determining $W$ chromosome morphology (Ws), are located on each side of this homologous region. Crossovers during female meiosis result in three atypical $W$ chromosomes (W1, W2 and W3 belonging to female 1219, and males 1026 and 1222 respectively). Another bomologous region $(\mathrm{Aw}=$ $\mathrm{Az}$ ) would contain the euchromatic part of both sex chromosomes, which includes the $\mathrm{W}$ short arm

the increased size of the W long arm, which is strongly heterochromatic especially in its distal part (Galetti and Foresti 1986). These cytogenetic studies have also shown that the long arm proximal part is composed of heterochromatic segments interspersed with euchromatin. These observations are strikingly compatible with our molecular data (L'46 and Ws separated by homologous regions) and also with our in situ hybridization results, which locate L'46 in the proximal region of the long arm. Crossovers would therefore affect homologous regions of both sex chromosomes containing the L'5 region (with two alleles L'5z and L'5w) and the sex-determining locus (with an active allele Sdw and an inactive counterpart Sdz). This model, illustrated in Fig. 6, explains the formation of three new $W$ chromosomes and three new $\mathrm{Z}$ chromosomes $(\mathrm{Z1}, \mathrm{Z} 2$ and $\mathrm{Z} 3$ ) in female meiosis, and these chromosomes would then predominantly be reassociated with normal $\mathrm{Z}$ chromosomes coming from $\mathrm{ZZ}$ males, giving rise to six new genotypes (see Table 2). Individuals 1219, 1026 and 1222 would thus have had the ZW1, ZW2 and ZW3 genotypes respectively. The absence of cases with atypical Z chromosomes in our animal collection may have been just a result of limited fish sampling, or have another explanation (inviability or sterility, causing their absence in a population of spawning adults). However, we cannot totally exclude the possibility that such chromosomes may have been recognized cytologically as a $W$, if the heterologous region containing L' 46 was long enough to allow their discrimination from a normal $\mathrm{Z}$ chromosome. This would allow ZZ3 genotypes to be included among ZW females classified as typical, but certainly not ZZ1 and ZZ2, because none of the individuals examined here had both a male pattern with L'5 and a female pattern with L'46.

\section{Mixed heterogametic systems suggested by sex-specific probes}

If we assume that single crossovers explain the patterns observed in our three atypical fish, a major question is whether they appeared in the parental generation or earlier. The former case implies a rather high frequency of crossovers, suggesting large distances between the loci or a telomeric position of at least three of them. In the second case, where atypical chromosomes would have appeared earlier and therefore be maintained in a sex chromosome polymorphism, we had a population comprising heterogametic females (ZW and ZW1), and homogametic and heterogametic males (ZZ, ZW2 and ZW3). A relationship between atypical sex chromosomes and meiotic exchanges (between non-homologous regions) is well documented in human, especially when these phenomena result in abnormal sex phenotypes. A number of $\mathrm{XX}$ males and $\mathrm{XY}$ females have thus been reported (de la Chapelle 1981; Disteche et al. 1986; Rouyer et al. 1987), but their frequencies are very low compared with those of normal XX females and $\mathrm{XY}$ males. A major difference in Leporinus is the much higher frequency of atypical sex chromosomes. We can explain it by frequent $\mathrm{Z}-\mathrm{W}$ recombinations in a pseudoautosomal segment (L'5, Sd) which reassociate two non-
Table 2. Sex chromosome complements and genotypes expected in the generation following a female meiosis, with three exchanges between $\mathrm{W}$ and $\mathrm{Z}$ chromosomes (see Fig. 6 and text for detailed explanations)

\begin{tabular}{lllllll}
\hline \multirow{2}{*}{$\begin{array}{l}\text { Sex } \\
\text { chromosome }\end{array}$} & Genotypes & & & $\begin{array}{l}\text { Ws } \\
\text { segment }\end{array}$ & $\begin{array}{l}\text { Sex } \\
\text { gonad }\end{array}$ & $\begin{array}{l}\text { Detection } \\
\text { here }\end{array}$ \\
\cline { 2 - 4 } & L'46 locus & L'5 locus & Sd locus & & & \\
\hline ZW & $0 / L^{\prime} 46$ & L'5z/L'5w & Sdz/Sdw & $0 /$ Ws & Female & 11 fish \\
ZZ & $0 / 0$ & L'5z/L'5z & Sdz/Sdz & $0 / 0$ & Male & 10 fish \\
ZW1 & $0 / 0$ & L'5z/L'5w & Sdz/Sdw & $0 / W s$ & Female & No. 1219 \\
ZW2 & $0 / 0$ & L'5z/L'5w & Sdz/Sdz & $0 / W s$ & Male & No. 1026 \\
ZW3 & $0 / 0$ & L'5z/L'5z & Sdz/Sdz & $0 / W s$ & Male & No. 1222 \\
ZZ1 & $0 / L^{\prime} 46$ & L'5z/L'5z & Sdz/Sdz & $0 / 0$ & Male & Not seen \\
ZZ2 & $0 / L^{\prime} 46$ & L'5z/L'5z & Sdz/Sdw & $0 / 0$ & Female & Not seen \\
ZZ3 & $0 / L^{\prime} 46$ & L'5z/L'5w & Sdz/Sdw & $0 / 0$ & Female & Not seen \\
\hline
\end{tabular}


homologous flanking regions (L'46, Ws) in variable ways. In terms of atypical chromosome frequencies, $L e$ porinus better recalls the wood lemming, Myopus schisticolor (Fredga et al. 1976) and the platyfish, Xiphophorus maculatus (Kallman 1984), where three sex chromosomes derive from a classical heterogametic system. The three systems may suggest how female heterogamety gradually appears from an XX/XY system, or how male heterogamety originates from a $Z Z / Z W$ system. Sex chromosome evolution in teleost fish clearly includes the repeated emergence of male and heterogametic systems in the different subtaxa. This has probably been the case for the genus Leporinus, since at least one species is cytologically reported as male heterogametic (Galetti et al. 1981). L. elongatus might be a contemporary witness of such a peculiar reversal of heterogametic systems.

Acknowledgements. This work has been supported in the frame of INRA assistance to foreign countries, INRA action on Y chromosome (ATP 4520) and INRA-IFREMER-Universities action on biological basis of aquaculture (GCS-BBA). We gratefully acknowledge N. Sanchez for her assistance during part of the work, D. Vaiman who performed preliminary experiments, S. Höller for her technical assistance in DNA sequencing, C. Cotinot, L.M. Houdebine and M. Kirszenbaum who stimulated the work by pertinent discussions, P. Planquette for the collection of Leporinus friderici samples from French Guyana, and CESP-Companhia Energética de Sao Paulo, which provided Leporinus elongatus and Leporinus friderici samples from Brazil.

\section{References}

Aida T (1921) On the inheritance of color in a fresh water fish, Aplocheilus latipes, with special reference to sex-linked inheritance. Genetics 6:554-573

Beçak W (1983) Evolution and differentiation of sex chromosomes in lower vertebrates. In: Müller U, Franke WW (eds) Mechanism of gonadal differentiation in vertebrates. Differentiation [Suppl] 23:S3-12

Charlesworth B (1991) The evolution of sex chromosomes. Science $251: 1030-1033$

Chourrout D, Quillet E (1982) Induced gynogenesis in the rainbow trout: sex and survival of progenies. Production of all-triploid populations. Theor Appl Genet 63:201-205

Clemens HP, Inslee T (1968) The production of unisexual broods of Tilapia mossambica sex-reversed with methyltestosterone. Trans Am Fish Soc 97:18-21

Cotinot C, Kirszenbaum M, Leonard M, Gianquinto L, Vaiman $M$ (1991) Isolation of bovine $Y$-derived sequence: potential use in embryo sexing. Genomics 10:646-653

de la Chapelle A (1981) Etiology of maleness in XX men. Hum Genet 58:105-116

Devereux J, Haeberli P, Smithies O (1984) A comprehensive set of sequence analysis programs for the VAX. Nucleic Acids Res $12: 387-395$

Devlin RH, McNeil BK, Groves TDD, Donaldson EM (1991) Isolation of a Y-chromosomal DNA probe capable of determining genetic sex in chinook salmon (Oncorhynchus tshawytscha). Can J Fish Aquat Sci 48:1606-1612

Disteche CM, Casanova M, Saal H, Friedman C, Sybert V, Graham J, Thuline H, Page DC, Fellous M (1986) Small deletions of the short arm of the $Y$ chromosome in 46,XY females. Proc Natl Acad Sci USA 83:7841-7844

Ferreiro C, Medrano JF, Gall GAE (1989) Genome analysis of rainbow trout and sturgeon with restriction enzymes and hybridization with a ZFY gene derived probe to identify sex. Aquaculture 81:245-251
Foerster W, Anders F (1977) Zytogenetischer Vergleich der Karyotypen verschiedener Rassen und Arten lebendgebärender Zahnkarpfen der Gattung Xiphophorus. Zool Anz 198:167-177

Fredga K, Gropp A, Winking H, Frank F (1976) Fertile XX and XY type females in wood lemming, Myopus schisticolor. Nature $261: 225-227$

Galetti PM Jr, Foresti F (1986) Evolution of the ZZ/ZW system in Leporinus (Pisces, Anostomidae). Cytogenet Cell Genet 43:43-46

Galetti PM Jr, Foresti F, Bertollo LAC, Moreira Filho O (1981) Heteromorphic sex chromosomes in three species of the genus Leporinus (Pisces, Anostomidae). Cytogenet Cell Genet 29:138-142

Galetti PM Jr, Foresti F, Bertollo LAC, Moreira Filho O (1984) Characterization of eight species of Anostomidae (Cypriniformes) fish on the basis of the nucleolar organizing region. Caryologia 37:401-406

Gordon M (1947) Genetics of Platypoecilius maculatus. IV. The sex-determining mechanism in two wild populations of the Mexican platy fish. Genetics 32:8-17

Guerrero RD (1975) Use of androgens for the production of allmale Tilapia aurea (Steindachner). Trans Am Fish Soc 2:342348

Haaf T, Schmid M (1984) An early stage of ZW/ZZ sex chromosome differentiation in Poecilia sphenops var. melanistica (Poeciliidae, Cyprinodontiformes). Chromosoma 89:37-41

Hickling CF (1960) The Malacca tilapia hybrids. J Genet 57:1-10

Hunter GA, Donaldson EM (1983) Hormonal sex control and its application to fish culture. In: Hoar WS, Randall DJ, Donaldson EM (eds) Fish physiology, vol 9B. Academic Press, New York, pp 223-303

Johnson DA, Gautsch JW, Sportsman JR, Elder JH (1984) Improved technique utilizing non fat dry milk for analysis of proteins and nucleic acids transferred to nitrocellulose. Genet Anal Tech 1:3-8

Kallman KD (1984) A new look at sex determination in poeciliid fishes. In: Turner BJ (ed) Evolutionary genetics of fishes. Plenum Press, New York, pp 95-171

Kessler C, Höltke HJ, Seibl R, Burg J, Mühlegger K (1990) Nonradioactive labelling and detection of nucleic acids. I. A novel DNA labelling and detection system based on digoxigenin: antidigoxigenin elisa principle (digoxigenin system). Biol Chem Hoppe-Seyler 371:917-927

Lamar EE, Palmer E (1984) Y-encoded, species specific DNA in mice: evidence that the Y-chromosome exists in two polymorphic forms in inbred strains. Cell 37:171-177

Lloyd MA, Fields MJ, Thorgaard GH (1989) Bkm minisatellite sequences are not sex associated but reveal DNA fingerprint polymorphism in rainbow trout. Genome 32:865-868

Nagy A, Rajki K, Horvath L, Csanyi V (1978) Investigation on carp, Cyprinus carpio, L. gynogenesis. J Fish Biol 13:215-224

Nanda I, Feichtinger W, Schmid M, Schröder JH, Zischler H, Epplen JT (1990) Simple repetitive sequences are associated with differentiation of the sex chromosomes in the guppy fish. J Mol Evol 30:456-462

Nanda I, Schartl M, Feichtinger W, Epplen JT, Schmid M (1992) Early stages of sex chromosome differentiation in fish as ana. lysed by simple repetitive DNA sequences. Chromosoma $101: 301-310$

Price DJ (1984) Genetics of sex determination in fishes - a brief review. In: Fish reproduction. Academic Press, New York, pp $77-89$

Rouyer F, Simmler MC, Page DC, Weissenbach J (1987) A sex chromosome rearrangement in a human $\mathrm{XX}$ male caused by Alu-Alu recombination. Cell 51:417-425

Sambrook J, Fritsch EF, Maniatis T (1989) Molecular cloning. A laboratory manual. Cold Spring Harbor Laboratory Press, Cold Spring Harbor, NY

Sanger F, Nicklen S, Coulson AP (1977) DNA sequencing with chain terminating inhibitors. Proc Natl Acad Sci USA 74:54635467 
Seibl R, Höltke HJ, Rüger R, Meindl A, Zachau HG, Rasshoffer $\mathrm{R}$, Roggendorf $\mathrm{M}$, Wolf $\mathrm{H}$, Arnold N, Weinberg J, Kessler $C$ (1990) Non radioactive labelling and detection of nucleic acids. III. Applications of the digoxigenin system. Biol Chem Hoppe-Seyler 371:939-951

Smith CL (1975) The evolution of hermaphroditism in fishes. In: Reinboth R (ed) Intersexuality in the animal kingdom. Springer, Berlin Heidelberg New York, pp 295-310

Sola L, Cataudella S, Capanna E (1981) New developments in vertebrate cytotaxonomy III. Karyology of bony fishes: a review. Genetica 54:285-328

Southern E (1975) Detection of specific sequences among DNA fragments separated by agarose gels. J Mol Biol 98:503-517
Thorgaard GH (1977) Heteromorphic sex chromosomes in male rainbow trout. Science 196:900-902

Thorgaard GH (1983) Chromosomal differences among rainbow trout, Salmo gairdneri populations. Copeia 1983:650-662

Yamamoto T (1953) Artificially induced sex reversal in genotypic males of the medaka (Oryzias latipes). J Exp Zool 123:571-594

Yamamoto T (1955) Progeny of artificially induced sex reversal of male genotype (XY) in the medaka (Oryzias latipes) with special reference to $Y Y$ male. Genetics 40:406-419

Zhang FR, Heilig R, Thomas G, Aurias A (1990) One step efficient and specific non radioactive non fluorescent method for in situ hybridisation of banded chromosomes. Chromosoma 99:436439 